\title{
DEVELOPMENT OF A HELIUM ATMOSPHERE SOIL INCUBATION TECHNIQUE FOR DIRECT MEASUREMENT OF NITROUS OXIDE AND DINITROGEN FLUXES DURING DENITRIFICATION
}

\author{
D. SCHOLEFIELD, ${ }^{*}$ J. M. B. HAWKINS ${ }^{\prime}$ and S. M. JACKSON ${ }^{2}$ \\ 'Institute of Grassland and Environmental Research, North Wyke, Okehampton, Devon EX20 2SB \\ U.K. and ' ${ }^{2}$ Department of Biological Sciences, University of Exeter, Exeter EX4 4PS, U.K.
}

\author{
(Accepted 7 January 1997)
}

\begin{abstract}
Summary - A technique is described in which the upper surfaces of intact soil cores are enveloped in a flowing atmosphere of $\mathrm{He}$ and $\mathrm{O}_{2}$ after first purging the soil and incubation vessel free from $\mathrm{N}_{2}$. This allows the independent measurement of $\mathrm{N}_{2} \mathrm{O}$ and $\mathrm{N}_{2}$ fluxes during denitrification of added or indigenous $\mathrm{N}_{3}^{-}-\mathrm{N}$ by direct flushing to twin gas chromatographs and without recourse to acetylene blocking. Square section cores are extracted from random locations in the field and assembled without air gaps to make composite turves in the incubation vessel, thus preserving field aerobicity and orientation but allowing the spatial variability in denitrification to be accommodated. An $\mathbf{N}_{\mathbf{2}}$-free irrigation assembly attached to each incubation vessel can be used to apply substrates during an experimental run, which is conducted in a temperature-controlled room. Use of the technique is demonstrated with measurements of $\mathrm{N}_{2} \mathrm{O}$ and $\mathrm{N}_{2}$ efflux from a wet, fine-textured soil under grassland management amended with nitrate and glucose. Peak concentrations were registered earlier than with previously-reported incubation techniques, with the flow rate of the incubation atmosphere having a substantial influence on the $\mathrm{N}_{2} \mathrm{O}$ to $\mathrm{N}_{2}$ ratio. Inclusion of acetylene as a component of the gas flow mixture stimulated denitrification and did not block $\mathrm{N}_{2}$ production completely. Application of the technique is limited by the extent to which atmospheric $\mathrm{N}_{2}$ contamination can be reduced and ultimately by the sensitivity of the gas chromatograph. The system in its present form has a detection limit for $\mathrm{N}_{2}$ from denitrification of about $50 \mathrm{~g} \mathrm{~N} \mathrm{ha}^{-1} \mathrm{~d}^{-1}$ and is therefore most suitably applied to soils under productive agricultural management. (C)1997 Elsevier Science Ltd
\end{abstract}

\section{INTRODUCTION}

Measurement of the rate of denitrification in soils has been the focus of intense research activity since the late $1970 \mathrm{~s}$. This upsurge in activity was prompted partly from an increased need to assess the economic and environmental impacts of denitrification in agricultural soils, which had, by then, begun to receive much larger inputs of fertilizer nitrogen. Another reason, however, was that two new techniques were then developed that promised more-accurate measurement of denitrification than had hitherto been possible.

The first of these was based on the addition of ${ }^{15} \mathrm{~N}$-enriched $\mathrm{NO}_{3}^{-}$to the soil and the subsequent measurement of the ${ }^{14} \mathrm{~N}-\mathrm{to}^{-15} \mathrm{~N}$ ratio in the two major gaseous products, $\mathrm{N}_{2} \mathrm{O}$ and $\mathrm{N}_{2}$, using a mass spectrometer. Whilst there are several shortcomings inherent in this technique (Hauk, 1987; Jenkinson et al., 1985) perhaps the greatest limitation to its routine use has been the high cost of the ${ }^{15} \mathrm{~N}$ -

\footnotetext{
*Author for correspondence.

†Present address: Department of Earth Sciences, Open University, Milton Keynes MK7 SAA, U.K.
}

enriched substrate and of the analytical instrumentation required. In contrast, the second of the new techniques, which is based on the inhibition of $\mathrm{N}_{2} \mathrm{O}$ reductase by acetylene (AI), is relatively cheap and extremely sensitive. Both the ${ }^{15} \mathrm{~N}$ and $\mathrm{AI}$ techniques have been used with field chambers (Ryden $e t$ al., 1979; Siegel et al., 1982) and in laboratory-based soil core incubations (Ryden et al., 1987) to make considerable progress in the study of denitrification. These techniques were and continue to be attractive because they circumvent the problem of direct measurement of the $\mathrm{N}_{2}$ produced by denitrification in an environment with an extremely large background concentration of $\mathrm{N}_{2}$.

Most progress has resulted from laboratory incubations of soil slurries and repacked, sieved soils, whereby the effects of the major controls on denitrification of nitrate, oxygen, water, temperature, carbon and $\mathrm{pH}$ have been quantified under standard conditions (e.g. Knowles, 1981). Despite the widespread use of the closed-incubation AI method developed by Ryden et al. (1979), comparatively little progress has been made in predicting the outcome of these controls in intact soils under field 
conditions (e.g. Jarvis et al., 1991). One of the reasons is the extent of spatial and temporal variability in denitrification that occurs in the field (Folorunso and Rolston, 1984), which is likely to be particularly great in productive grassland soils receiving frequent top dressings of fertilizer and the excretal returns from grazing animals.

Another reason for poor prediction of denitrification rates in the field may be the potential shortcomings inherent in the AI technique itself. These include the inhibitory effect of $\mathrm{C}_{2} \mathrm{H}_{2}$ on nitrification, the role of $\mathrm{C}_{2} \mathrm{H}_{2}$ as a carbon substrate and, possibly the most important, the incomplete inhibition of $\mathrm{N}_{2} \mathrm{O}$ reductase under the very conditions that promote denitrification (Pain et al., 1990). Further problems with existing soil core incubation techniques that few researchers have paid heed to relate to the need to regulate the concentration and rate of supply of $\mathrm{O}_{2}$ in the incubation vessel to the values obtained in soil in the field. While the effect of $\mathrm{O}_{2}$ concentration has been shown to be extremely large (Arah et al., 1991), the basis for its regulation during incubation are likely to be more complicated than simply the regulation of concentration per se. To preserve the "natural" $\mathrm{O}_{2}$ gradients in cores by exposing only their upper surfaces to an atmosphere containing $20 \% \mathrm{O}_{2}$ is also likely to be important.

To minimize the cconomic and environmental effects of denitrification, models are required that accurately predict rates of denitrification in the field. Such models require sound data on which to be based or tested against. In view of the many shortcomings of existing methodology, particularly in relation to measurement in systems highly heterogeneous in nitrate and $C$ supply and in wet, fine textured soils, a novel soil core incubation technique has been developed. This is based upon a technique used by Stefanson (1970) and Stefanson and Greenland (1970) whereby the $\mathrm{N}_{2}$ in a gas-tight plant growth chamber was wholly replaced by Ar, thus allowing the direct and independent measurement of both $\mathrm{N}_{2} \mathrm{O}$ and $\mathrm{N}_{2}$ during denitrification. The technique was developed by Wickramasinghe $e t$ al. (1978) and Galsworthy and Burford (1978) specifically to measure the gaseous products of denitrification under anaerobic conditions in small repacked soil samples using $\mathrm{He}$ and $\mathrm{Ar}$, respectively, as the replacement atmosphere. We report further developments that comprise (1) novel soil sampling and incubation methods that allow statistically representative measurements on intact field cores; (2) the facility to maintain natural gradients in $\mathrm{O}_{2}$ concentration within the cores; (3) a $\mathrm{N}_{2}$-free irrigation assembly attached to each incubation vessel to allow additions of water and soluble substrates during an experimental run; and (4) increased sensitivity to $\mathrm{N}_{2}$ evolution by use of an injection valve fitted with a He purge envelope. The operation of the technique is demonstrated with the measurement of $\mathrm{N}_{2} \mathrm{O}$ and $\mathrm{N}_{2}$ evolved from wet intact cores of an impermeable clay loam soil under grazed grassland management amended with $\mathrm{KNO}_{3}$ and glucose. The effects of variation in the gas flow rate and of the addition of $\mathrm{C}_{2} \mathrm{H}_{2}$ are also reported.

\section{MATERIALS AND METHODS}

\section{Soil sampling and experimental site}

Soil was sampled from an experimental plot at The Institute of Grassland and Environmental Research, North Wyke, Devon, U.K. The soil is a clayey pelostagnogley (stagno-Dystric Gleysol) of the Hallsworth Series (Clayden and Hollis, 1984). In the $0-100-\mathrm{mm}$ layer, the inorganic fraction comprised $36.6 \%$ clay, $47.7 \%$ silt, $13.9 \%$ fine sand and $1.8 \%$ coarse sand, the content of organic $\mathrm{C}$ was 5.3\% (Armstrong and Garwood, 1991) and the $\mathrm{pH}$ $\left(\mathrm{H}_{2} \mathrm{O}\right)$ was 5.7. Soil cores were taken during the winters of 1992-93 and 1993-94 from random locations in a 0.66 -ha plot that had been grazed by beef cattle in summer but had received no $\mathrm{N}$ fertilizer for at least 10 years. The soil on this plot had very small nitrate concentrations (Scholefield et al., 1993).

Purpose-built square-section corers were used to obtain the intact soil samples required with this technique. The corer was constructed from a sleeve made from $1 \mathrm{~mm}$-thick box-section mild steel with a sharpened stainless steel cutter welded at one end with dimensions $(45 \times 45 \mathrm{~mm})$, slightly smaller than those of the sleeve to reduce any tendency of soil sticking in the corer. The cores could be taken manually down to $140 \mathrm{~mm}$ depth without undue effort by making use of the two foot brackets welded to the corer sleeve and handles mounted at about waist height on a " $T$ " bar. Each extracted core was reduced in length to $90 \mathrm{~mm}$ by carefully paring the base with a sharp blade. Thus, the growing plant was normally left attached to the core, after reducing the bulk of herbage by either mowing prior to sampling, or clipping prior to incubation. In each experimental run, 150 cores (ca. $30 \mathrm{~kg}$ soil) were used. The cores were placed randomly with vertical alignment in six incubation vessels with each vessel holding 25 cores fitted exactly in a $5 \times 5$ array (Fig. 1). Two people could sample, prepare the cores and load the incubation vessels in less than $2 \mathrm{~h}$. The objective was to transfer the cores from the field to the vessels as quickly and carefully as possible in order to preserve $\mathrm{O}_{2}$ status and minimize compression and gaps between cores

\section{The incubation system and experimental procedure}

The incubation vessels were made from $12 \mathrm{~mm}$ thick ABS plastic sheet with internal dimensions of $225 \times 225 \times 120 \mathrm{~mm}$, resulting in an enclosed volume of 6.071 , of which 4.561 was occupied by soil. The cores were placed on a wire mesh raised 

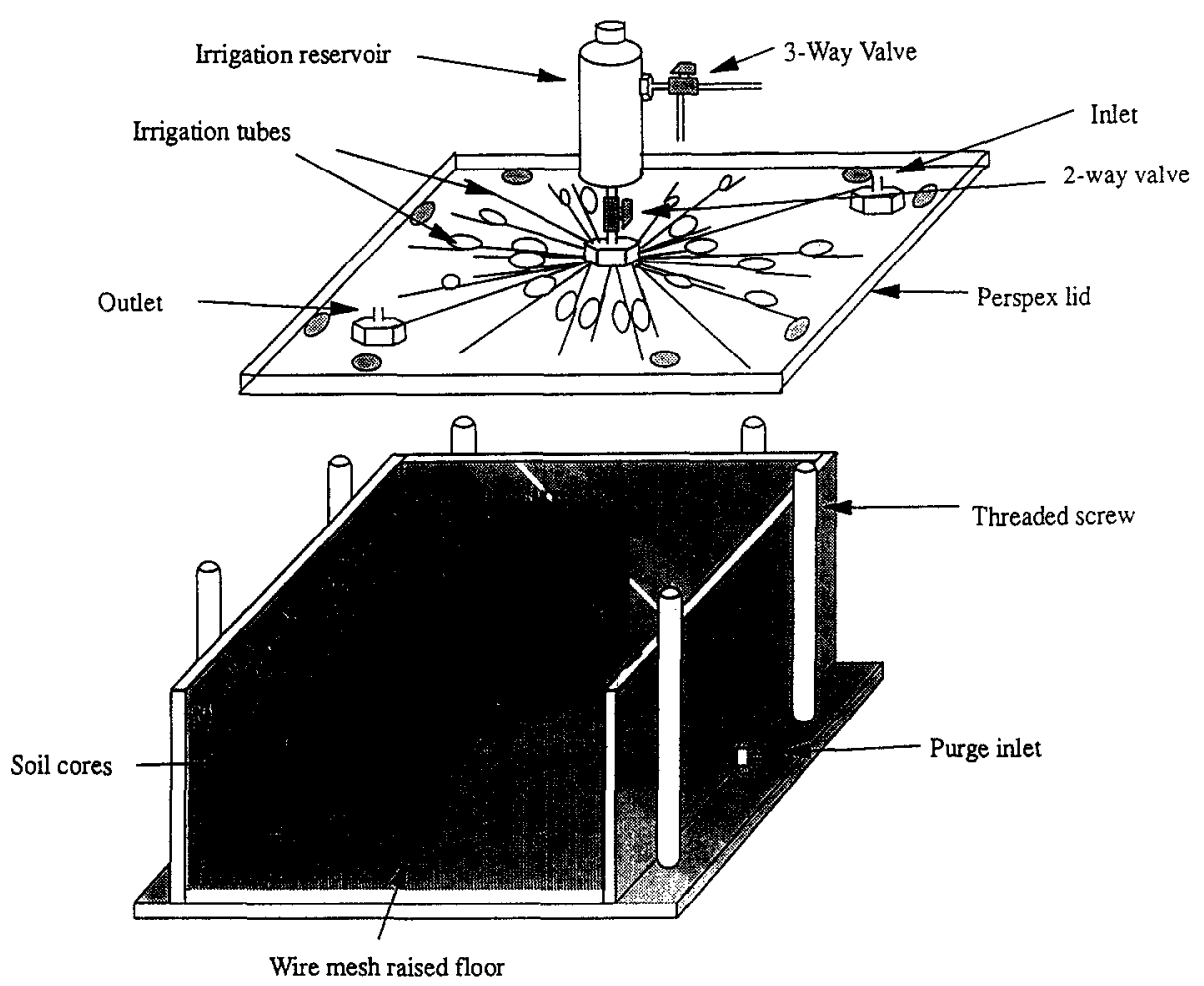

Fig. 1. Exploded view of an incubation vessel showing soil cores and irrigation assembly for application of $\mathrm{N}_{2}$-free substrates to the soil surface.

$5 \mathrm{~mm}$ above the floor of the vessel. One gas inlet was located beneath the wire mesh and a second in the lid opposite to the single outlet.

At the start of an experimental run, $\mathrm{NO}_{3}^{-}$, glucose, water and any other amendments could be applied to the surface of the cores either manually, or by using the He-purged irrigation assembly. One advantage of using the irrigation assembly was that $\mathrm{N}_{2}$ could be measured immediately, whereas after manual application this measurement had to be delayed until the original soil atmosphere had been replaced.

The soil atmosphere was replaced by purging the incubation vessel with a mixture of $\mathrm{O}_{2}$ and $\mathrm{He}$ through the lower inlet at a rate of $180 \mathrm{ml} \mathrm{min}^{-1}$ for $17 \mathrm{~h}$. These purging conditions were determined as optimal for removal of all $\mathrm{N}_{2}$ by conducting a series of tests using mixtures of pure, acid-washed sand and kaolinite clay in different proportions, packed in the incubation vessels, each at a range of water contents.

The proportion of $\mathrm{O}_{2}$ in the mixture was adjusted to that measured in gas diffusion probes inserted at the appropriate depth in the field, but this was rarely less than $10 \%$. Flow rates were adjusted to give the correct mixture before the gases were passed via a glass sinter through water to reduce any tendency for soil desiccation during a run. The purging gas was then routed to each incubation vessel through a six-way manifold. Effluent gases from each vessel could be either switched to a six- way valve for analysis by the gas chromatographs, or through a gas flow meter and then to waste via a water trap.

After replacement of soil atmosphere, any amendments were added via the irrigation assembly and the gas flow was switched to "flow-over" mode, using the inlet in the lid of the vessel. The gas mixture was adjusted to $20 \% \mathrm{O}_{2}$ in $\mathrm{He}$ and the flow rate to $20 \mathrm{ml} \mathrm{min}^{-1}$. It was envisaged that, at this stage, $\mathrm{O}_{2}$ gradients would have been set up in the soil that were similar to those present under the same conditions in the field. However, the flow paths of gas over the soil surface were not characterized directly. The fact that repeated injections of the same volume of $\mathrm{N}_{2} \mathrm{O}$ into the inlet line resulted in very similar traces measured at the gas chromatograph was taken as evidence of uniform mixing within the headspace. Total gas flow through each vessel per experimental run was measured using the in-line gas meter.

Measurement of $\mathrm{N}_{2}$ was made using a gas chromatograph (Pye 104) fitted with a He-purged injection valve (Valco, Phase Separations, Deeside, U.K.) containing a 1-ml sample loop, a thermal conductivity detector and a column $(2 \mathrm{~m}$ in length with a 3 -mm bore) packed with a $5 \AA$ molecular sieve of $80-100$ mesh (Phase Separations, Deeside, U.K.) (see Fig. 2). The carrier gas was He flowing at $30 \mathrm{ml} \mathrm{min}^{-1}$ and the temperatures of the oven and detector were 50 and $60^{\circ} \mathrm{C}$, respectively. This system enabled good separation of the $\mathrm{O}_{2}$ and $\mathrm{N}_{2}$ 


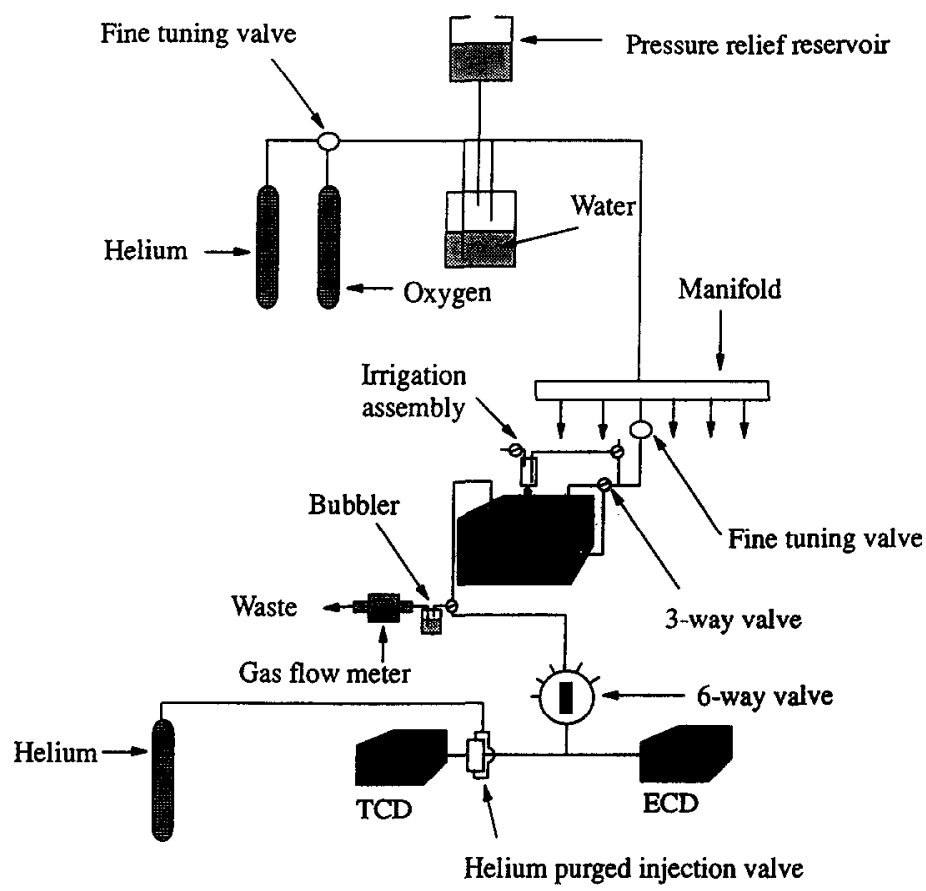

Fig. 2. Schematic diagram of flow-through incubation system showing one of six incubation vessels in the gas flow path from cylinders of $\mathrm{He}$ and $\mathrm{O}_{2}$ to twin gas chromatographs, one fitted with a thermal conductivity detector (TCD) for measurement of $\mathrm{N}_{2}$ and the other with an electron capture detector

(ECD) for measurement of $\mathrm{N}_{2} \mathrm{O}$.

peaks which were eluted after two and $7 \mathrm{~min}$ respectively. Measurement of $\mathrm{N}_{2} \mathrm{O}$ was made using a second g.c. (Pye 4500) fitted with an electron capture detector and a column ( $2 \mathrm{~m}$ length, $4 \mathrm{~mm}$ bore) packed with "Porapak Q" of 80-100 mesh. The carrier gas was $\mathrm{N}_{2}$ flowing at $40 \mathrm{ml} \mathrm{min}^{-1}$ and the temperatures of the oven and detector were 85 and $350^{\circ} \mathrm{C}$, respectively. The minimum time required to measure both $\mathrm{N}_{2} \mathrm{O}$ and $\mathrm{N}_{2}$ (and $\mathrm{O}_{2}, \mathrm{CO}_{2}$ and $\mathrm{NO}$ if required) in effluent from all six vessels was $47 \mathrm{~min}$ but readings were normally repeated every $2-3 \mathrm{~h}$. The system was operated in an air-conditioned room with temperature controlled to $\pm 1^{\circ} \mathrm{C}$. An experimental run was continued until concentrations of $\mathrm{N}_{2} \mathrm{O}$ and $\mathrm{N}_{2}$ had returned to near background, which normally took 5-8 d. After each run, the soil in each vessel was mixed, sub-sampled and analysed colorimetrically for $\mathrm{NO}_{3}^{-}, \mathrm{NH}_{4}^{+}$and water content. Thus, $100 \mathrm{~g}$ samples were mixed with $200 \mathrm{ml}$ of $1.0 \mathrm{M} \mathrm{KCl}$ and shaken for $2 \mathrm{~h}$. The supernatants were filtered and analysed for $\mathrm{NO}_{3}^{-}$and $\mathrm{NH}_{4}^{+}$ using an auto-analyser (Skalar, Utrecht, The Netherlands). Water content was determined gravimetrically on further samples of the remaining soil.

\section{Denitrification measurements}

A major technical difficulty in the design, construction and operation of this technique was the need to minimize the extent of leakage of laboratory atmosphere into the apparatus. Despite the precautions against atmospheric contamination embodied in the system, the signal-to-noise ratio for the $\mathrm{N}_{2}$ measurement remained a major limitation to the sensitivity of this technique and therefore the range of its application. The contribution to $\mathrm{N}_{2}$ contamination from diffusion through the walls of the incubation vessel and tubing was estimated, with data obtained from the manufacturers, at $10 \%$ of the total. However, it is the variability in the "background" $\mathrm{N}_{2}$ concentration that determines the sensitivity of the system for measuring $\mathrm{N}_{2}$ derived from denitrification. Thus, it was assumed that the limit of detection for $\mathrm{N}_{2}$ was $16 \mu 11^{-1}$ above background, which is equivalent to ca. $50 \mathrm{~g} \mathrm{~N} \mathrm{ha}^{-1} \mathrm{~d}^{-1}$. The limit of detection for $\mathrm{N}_{2} 0$ was ca. $60 \mathrm{nl} \mathrm{l}^{-1}$, which is equivalent to ca. $170 \mathrm{mg} \mathrm{N} \mathrm{ha}^{-1} \mathrm{~d}^{-1}$ at a flow rate of $20 \mathrm{ml} \mathrm{min}^{-1}$. Fluxes of $\mathrm{N}_{2} \mathrm{O}$ and $\mathrm{N}_{2}$ were calculated on a ha ${ }^{-1}$ basis by multiplying the concentration of each gas measured at the appropriate g.c. by the volume of gas passed through each vessel since the last measurement and then multiplying by the ratio of 1 ha to the area of soil per vessel.

The technique has been used to measure the effects of the major controls on denitrification in an intact clay soil under grazed grassland. Only those results relevant to the development and evaluation of the technique are reported here, which are: (1) the effects of gas flow rate; (2) the effects of $\mathrm{C}_{2} \mathrm{H}_{2}$; (3) effects of $\mathrm{He}$ as the replacement atmosphere and (4) the effects of size of soil core on the variability in denitrification. Unless otherwise stated, the experimental conditions were: $\mathrm{KNO}_{3}$ and glucose applied in aqueous solution at rates equivalent to 
100 and $394 \mathrm{~kg} \mathrm{ha}^{-1}$ of $\mathrm{N}$ and $\mathrm{C}$, respectively; gas flow rate of $20 \mathrm{ml} \mathrm{min}^{-1}$, soil water content of ca. $40 \%(\mathrm{v} / \mathrm{v})$ and temperature of $20^{\circ} \mathrm{C}$. Flow rate was investigated by comparing the results of experimental runs performed at 5 and $80 \mathrm{ml} \mathrm{min}^{-1}$. The effect of $\mathrm{C}_{2} \mathrm{H}_{2}$ (at $8 \% \mathrm{v} / \mathrm{v}$ ) was measured for continuous flow and static incubations.

The replacement of $\mathrm{N}_{2}$ with $\mathrm{He}$ can be questioned on the grounds that $\mathrm{He}$ is a much smaller molecule that might result in more rapid rates of diffusion of the products of denitrification through soil atmosphere. If the residence time of $\mathrm{N}_{2} \mathrm{O}$ was shortened significantly, this could, in turn, lead to a different ratio of products. The amount of $\mathrm{N}_{2} \mathrm{O}$ and its rate of efflux were therefore measured using either $\mathrm{He}$ or $\mathrm{N}_{2}$ as the major component of the replacement atmosphere. The production of $\mathrm{N}_{2}$ could, of course, not be measured. The effects of core size and number were examined simply by a comparison of the variability in denitrification measured using the standard procedure with that resulting from incubation of six large soil blocks (one per vessel) each of dimensions $225 \times$ $225 \times 90 \mathrm{~mm}$, sampled from random locations in the field.

\section{RESULTS AND DISCUSSION}

Figure 3 shows a typical pattern of denitrification produced by the system; the rate of efflux of $\mathrm{N}_{2} \mathrm{O}$ increased almost linearly with time during the first day after addition of the amendments to peak at ca. $10.5 \mathrm{~kg} \mathrm{~N} \mathrm{ha}^{-1} \mathrm{~d}^{-1}$ after $30 \mathrm{~h}$. The $\mathrm{N}_{2}$ peak was smaller but broader and was reached almost $1 \mathrm{~d}$ later than the $\mathrm{N}_{2} \mathrm{O}$ peak. Efflux of $\mathrm{N}_{2} \mathrm{O}$ declined to a very small rate after $4 \mathrm{~d}$, whereas efflux of $\mathrm{N}_{2}$ continued at rates greater than $1.0 \mathrm{~kg} \mathrm{~N} \mathrm{ha}^{-1} \mathrm{~d}^{-1}$ until the end of the run. Of the $100 \mathrm{~kg} \mathrm{~N} \mathrm{ha}^{-1}$ added, only $51.7 \mathrm{~kg} \mathrm{ha}^{-1}$ could be accounted for as $\mathrm{N}_{2} \mathrm{O}\left(22.4 \mathrm{~kg} \mathrm{~N} \mathrm{ha}^{-1}\right)$ and $\mathrm{N}_{2}\left(29.3 \mathrm{~kg} \mathrm{Nha}^{-1}\right)$. Analysis of the soil after the run revealed that much of the remaining $\mathrm{N}$ was as $\mathrm{NH}_{4}^{+}(37.4 \mathrm{~kg}$

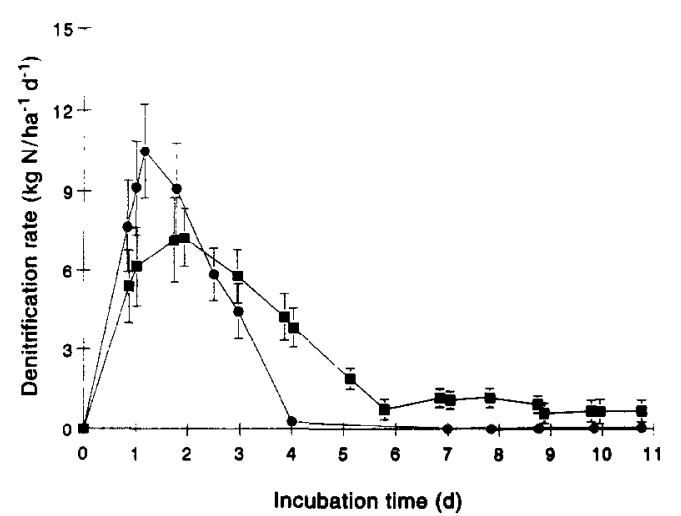

Fig. 3. The evolution with time of $\mathrm{N}_{2} \mathrm{O}(\bullet)$ and $\mathrm{N}_{2}(\mathbf{\square})$ during incubation of a clay loam soil at $40 \%$ water content $(\mathrm{v} / \mathrm{v})$ and $20^{\circ} \mathrm{C}$, amended with $\mathrm{NO}_{3}^{-}$and glucose. $\mathrm{ha}^{-1}$ ), with only a small amount as free $\mathrm{NO}_{3}^{-}$ $\left(2.8 \mathrm{~kg} \mathrm{~N} \mathrm{ha}^{-1}\right.$ ). It was therefore possible that some of the $\mathrm{N}_{2} \mathrm{O}$ could have been produced as a result of nitrification, but this would have been small as gauged by the $\mathrm{N}_{2} \mathrm{O}$ efflux at $4 \mathrm{~d}$, when $\mathrm{NH}_{4}^{+}$concentrations were presumably quite large. Although $>90 \%$ of the $\mathrm{N}$ applied could apparently be accounted for, data reported by Scholefield et al. (1997) show that the proportion accounted for decreases with the amount of $\mathrm{N}$ applied. This crude balance takes no account of $\mathbf{N}$ mineralization, assimilation into biomass, plant uptake or $\mathrm{N}_{2}$-fixation and is therefore of limited use as an indicator of leaks. Judging from the large amounts of residual $\mathrm{NH}_{4}^{+}, \mathrm{NO}_{3}^{-}$assimilation could have been important, whereas because of the strong $\mathrm{NO}_{3}^{-}$concentrations and low $\mathrm{pH}$, we would expect $\mathrm{N}_{2}$ - fixation to be rather unimportant. The presence of the long $\mathrm{N}_{2}$ "tail" on most of the traces can be attributed to denitrification of relatively small concentrations of $\mathrm{NO}_{3}^{-}$produced from nitrification. The data reported by Scholefield et al. (1997) confirm that the $\mathrm{N}_{2} \mathrm{O}-$ to- $\mathrm{N}_{2}$ ratio become very small with $\mathrm{NO}_{3}^{-}$concentrations smaller than $5 \mathrm{~kg} \mathrm{~N} \mathrm{ha}^{-1}$.

This pattern of gas efflux is similar to those obtained by others working with re-packed, airdried sieved soils (e.g. Nommik, 1956; Wickramasinghe et al., 1978; Ryden et al., 1979; Letey et al., 1980; Cho, 1982). In these earlier studies, however, peak efflux of both gases tended to be reached later. There are several possible reasons for this. One is that the enzymes necessary for nitrate and nitrous oxide reduction were not present after air-drying and had to be produced de novo after the onset of anaerobiosis. A study of the dynamics of the reduction enzymes in the Rowden soil (Dendooven and Anderson, 1994) showed that although nitrate reductase is rather persistent and can survive aerobic periods, nitrous oxide reductase cannot and must be re-synthesized.

Nommik (1956) showed that $\mathrm{pH}$ is also an important regulator of denitrification rate: the lower the $\mathrm{pH}$ the slower the process and the greater the $\mathrm{N}_{2} \mathrm{O}$-to- $\mathrm{N}_{2}$ ratio in the product. Another reason for the relatively rapid denitrification rates apparent with the present system may be that more rapid fluxes through and from the soil are facilitated. Diffusion from the active micro-sites to the soil surface may well be more rapid with intact, well-structured cores than with repacked or slurried soils. In addition, the diffusion gradients would be kept steep by continual removal of products with the present "flow over" system, whereas with closed or re-circulating systems the diffusion gradients would decline during the course of the incubation. The rate of removal of products may have contributed to a large effect on the $\mathrm{N}_{2} \mathrm{O}$-to- $\mathrm{N}_{2}$ ratio and the timing of the $\mathrm{N}_{2} \mathrm{O}$ peak (Fig. 4). At the higher flow 

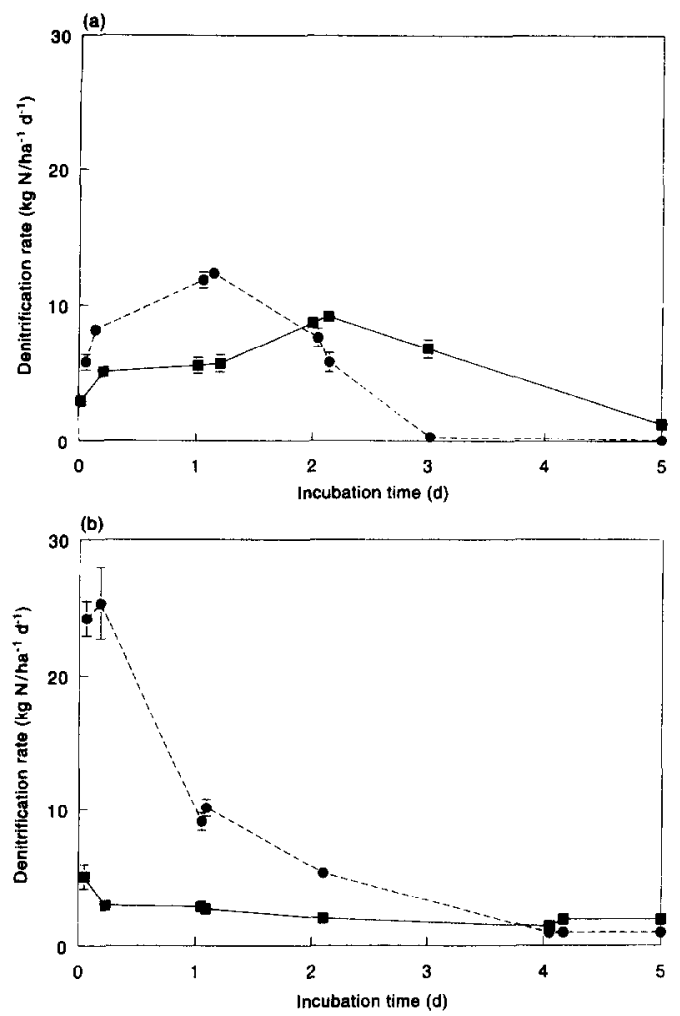

Fig. 4. Effect of gas flow rate on evolution of $\mathrm{N}_{2} \mathrm{O}(\bullet)$ and $\mathrm{N}_{2}$ (品) with time at (a) $5 \mathrm{ml} \mathrm{min}-1$ and (b) $80 \mathrm{ml} \mathrm{min}^{-1}$, during incubation of a clay loam soil at $40 \%$ water content $(\mathrm{v} / \mathrm{v})$ and $20^{\circ} \mathrm{C}$ and amended with glucose.

rate of $80 \mathrm{ml} \mathrm{min}^{-1}, \mathrm{~N}_{2} \mathrm{O}$ was the major product, the peak concentration was doubled compared to that produced at $5 \mathrm{ml} \mathrm{min}-1$ and was registered after only $8 \mathrm{~h}$. This result, which has important implications for the effects of windspeed on the products of denitrification in the field, could have been due partly to effectively greater oxygenation of the soil surface with the greater flow rate. Parkin et al. (1984), using a recirculating gas-flow core incubation technique with $\mathrm{AI}$ to estimate field denitrification, showed that greater rates of denitrification were obtained with forced air flow than with a static system, but this they attributed to increased effectiveness of AI rather than removal of products. It is clear that while denitrification rate per se may be insensitive to factors affecting gaseous transport, the environmental effects of denitrification (the proportion of $\mathrm{N}_{2} \mathrm{O}$ in the gases produced) is greatly influenced by these factors during the few days following an addition of fertilizer.

The use of the He atmosphere might be expected to have increased diffusion rates from the soil since the diffusivity of $\mathrm{N}_{2} \mathrm{O}$ in $\mathrm{He}$ is 30 times that in $\mathrm{N}_{2}$ (Fuller et al., 1966). However, our investigation proved that neither the amount nor the rate of $\mathrm{N}_{2} \mathrm{O}$ efflux was influenced substantially by the use of $\mathrm{He}$ (data not presented). This result agrees with those of Blackmer and Bremner (1977) and indicates that
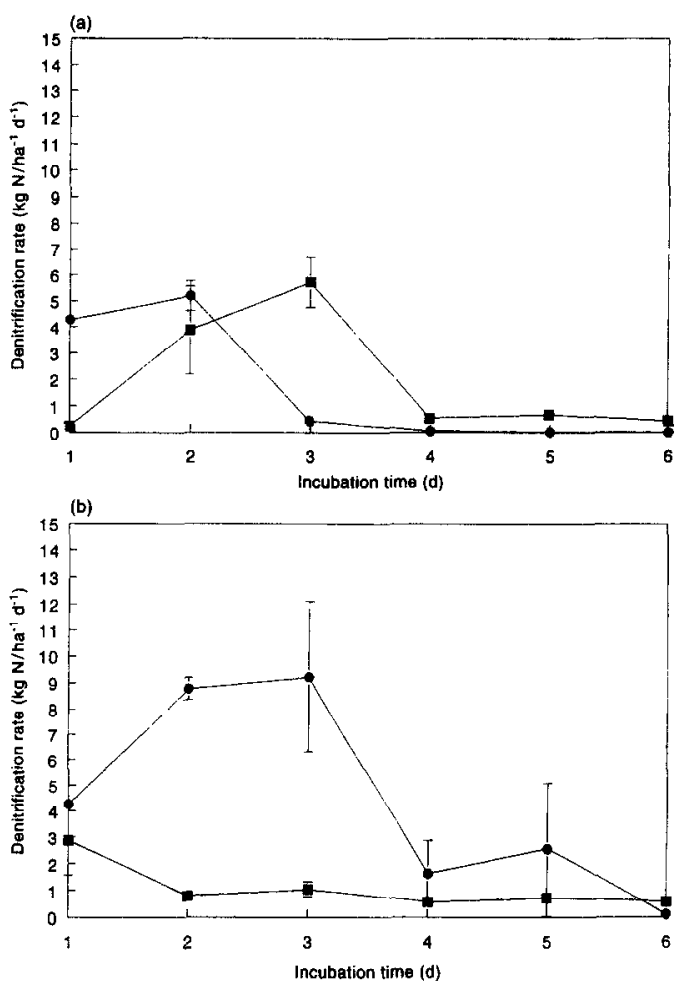

Fig. 5. Evolution of $\mathrm{N}_{2} \mathrm{O}(\bullet)$ and $\mathrm{N}_{2}(\square)$ with time (a) without or (b) with $\mathrm{C}_{2} \mathrm{H}_{2}$, during the incubation of a clay loam soil at $40 \%$ water content $(v / v)$ and $20^{\circ} \mathrm{C}$ and amended with glucose.

it is the water films rather than the atmosphere that control the rate of diffusion of gaseous products.

With such rapid diffusion of denitrification products away from the soil, it might be argued that $\mathrm{C}_{2} \mathrm{H}_{2}$ would diffuse rapidly to the active micro-sites and be relatively efficient in blocking $\mathrm{N}_{2} \mathrm{O}$ reductase even in wet clay soils. Figure 5 shows that this was not the case: $\mathrm{C}_{2} \mathrm{H}_{2}$ blocking was particularly inefficient during the first day of incubation and only ca. $80 \%$ efficient overall. This is contrary to the findings of Ryden et al. (1979) but supports the suspicions of Arah et al. (1991) and Pain et al. (1990). An additional effect was an apparent stimulation of the denitrification process, which Haider et al. (1983) attributed to increased $C$ mineralization, but which could be accounted for simply by a reduction in the partial pressure of $\mathrm{O}_{2}$ through displacement by the $\mathrm{C}_{2} \mathrm{H}_{2}$ (e.g. Arah et al., 1991).

The variability in the measurements of denitrification was large, with the coefficient of variation in flux of both $\mathrm{N}_{2} \mathrm{O}$ and $\mathrm{N}_{2}$ being typically about $40 \%$ and ranging from 11 to $105 \%$ for the data presented. The coefficient of variation in flux remained small throughout some runs but varied considerably between consecutive measurements in others [e.g. 55(b)]. These values are somewhat smaller than those reported for variability in denitrification in field soils, possibly because our measurements were 
performed on very wet, clay soils. For example, Robertson et al. (1988) obtained a value of $275 \%$ from measurements made on 301 samples of a sandy loam and Folorunso and Rolston (1984) obtained a range of $282-379 \%$ for $\mathrm{N}_{2} \mathrm{O}$ measurements on Yola loam using field chambers. In contrast, much smaller coefficients of variation were determined between repeated measurements of short duration made on the same soil samples (Parkin et al., 1984). Similar repeated runs with the present technique would not be expected to reduce variabilty because the amount and activity of the different reductase enzymes originally present would be changed on addition of $\mathbf{N}$ and $\mathrm{C}$. Furthermore, with prolonged incubation, the plants would begin to die and decay. For these reasons, comparison of the patterns of gas efflux from soil collected from the same location, but at different times (as in our study) will not be a good estimate of the reproducibility of the technique: different antecedent conditions would have caused each sample to respond differently to the substrates applied and conditions imposed. One source of variability in our study was the application of substrates made via the irrigation assembly (Fig. 1). The coefficient of variation in the volume of solution applied to each core (nominally $2 \mathrm{ml}$ ) over three applications was $16.7 \%$. However, the actual distributions of $\mathrm{NO}_{3}$ and $\mathrm{C}$ in the soil would have been determined more by the rate and pattern of infiltration into each core.

The other major source of variability in denitrification would have been the spatial variability of the soil physical and biochemical properties in the field and their interaction with the sampling procedure The use of fewer, larger cores did result in a substantial increase in variability and also a change in the pattern of $\mathrm{N}_{2} \mathrm{O}$ efflux (Fig. 6). The appearance of a second peak after $2.5 \mathrm{~d}$ was presumably due to a reduced number of unnatural vertical cracks in the larger cores: the first peak may have been due to gas produced at or near the soil surface, but the second to delayed diffusion of gas produced deeper in cores at sites remote from cracks. A possible advantage in using fewer, larger cores that may offset the reduced precision obtainable is that any effects due to mechanical damage to the plant (e.g. Beck and Christensen, 1987) might be minimized. The Rowden soil was evidently rich in easily degradable organic matter as the effects on denitrification of plant cutting, addition of glucose and diurnal variations in light intensity were rather small (data not shown).

Because of the limitations to $\mathrm{N}_{2}$ detection caused by a narrow signal-to-noise ratio and poor gas chomatographic sensitivity, it can be concluded that the technique described may be most useful for measuring fluxes of $\mathrm{N}_{2} \mathrm{O}$ and $\mathrm{N}_{2}$ (and $\mathrm{CO}_{2}$ and $\mathrm{O}_{2}$ if required) from fine textured soils under agricultural rather than extensive or "semi-natural" man-
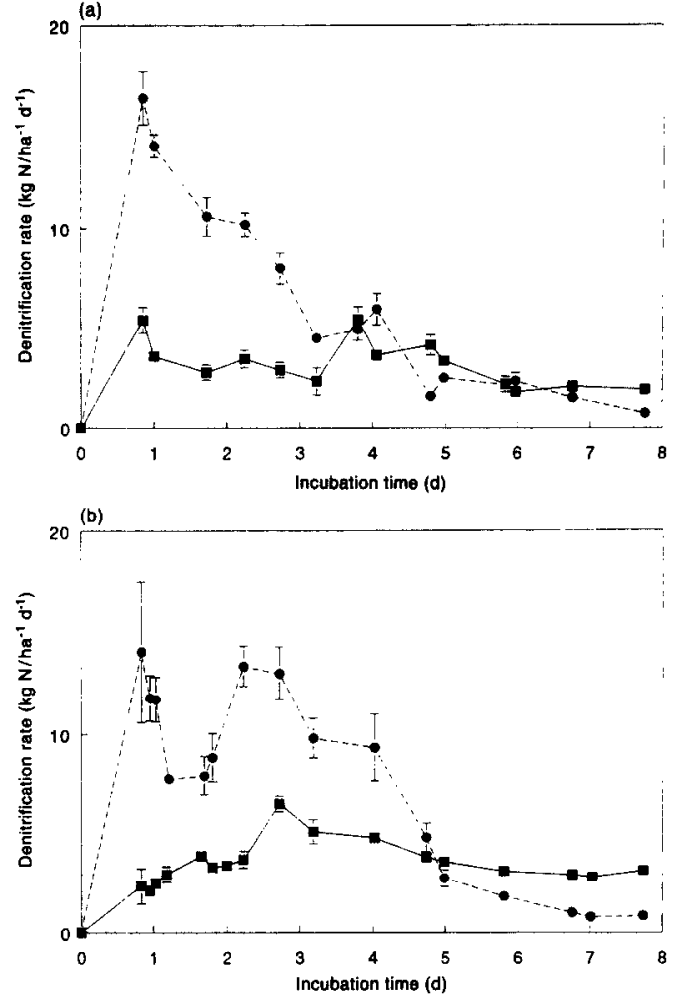

Fig. 6. Evolution of $\mathrm{N}_{2} \mathrm{O}(\bullet)$ and $\mathrm{N}_{2}(\square)$ with time from incubation of (a) 150 small cores, or (b) six large cores of a clay loam soil at $40 \%$ water content $(\mathrm{v} / \mathrm{v})$ and $20^{\circ} \mathrm{C}$ and amended with glucose.

agements. The advantages of the technique over those reported previously, however, is that $\mathrm{N}_{2} \mathrm{O}$-to$\mathrm{N}_{2}$ ratios can be obtained directly with the same sample of soil without recourse to $\mathrm{AI}$ and that the important influences of gas transport can be readily investigated with intact field soils. Further developments could include automation and computer control of the valves, temperature programming of the laboratory and the provision of lights to illuminate the plants.

Acknowledgements-We are grateful to Alan Haley at the Hatherley Laboratories for making the incubation vessels and to Dr S. C. Jarvis for comments on an early draft. The research was in part funded through a Link Grant from the Biotechnology and Biological Sciences Research Council.

\section{REFERENCES}

Arah J. R. M., Smith K. A., Crichton I. J. and Li H S. (1991) Nitrous oxide production and denitrification in Scottish arable soils. Journal of Soil Science 42, 351367.

Armstrong A. C. and Garwood E. A. (1991) Hydrological consequences of artificial drainage of grassland. Hydrological Processes 5, 157-174.

Beck H. and Christensen S. (1987) The effect of grass maturing and root decay on $\mathrm{N}_{2} \mathrm{O}$ production in soil. Plant and Soil 103, 269-273. 
Blackmer A. M. and Bremner J. M. (1977) Denitrification of nitrate under different atmospheres. Soil Biology \& Biochemistry 9, 141-142.

Cho C. M. (1982) Oxygen consumption and denitrification kinetics in soil. Soil Science Society of America Journal 46, 756-762.

Clayden B. and Hollis J. M. (1984) Criteria for differentiating soil series. In Soil Survey of England and Wales. Technical Monograph No. 17, Harpenden Lawes Agricultural Trust.

Dendooven L. and Anderson J. M. (1994) Dynamics of reduction enzymes involved in the denitrification process in pasture soil. Soil Biology \& Biochemistry 26, 15011506.

Folorunso O. A. and Rolston D. E. (1984) Spatial variability of field-measured denitrification gas fluxes. Soil Science Society of America Journal 48, 1214-1219.

Fuller E. N., Shettler P. D. and Giddings P. D. (1966) A new method for predicting binary gas-phase diffusion coefficients. Industrial and Engineering Chemistry 58, 18 27.

Galsworthy A. M. and Burford J. R. (1978) A system for measuring the rates of evolution of nitrous oxide and nitrogen from incubated soils during denitrification. Journal of Soil Science 29, 537-550.

Haider K., Mosier A. R. and Heinemeyer O. (1983) Side effects of acetylene on the conversion of nitrate in soil. Zeitschift fur Pfanzenernahrung und Bodenkunde 146, 623-633.

Hauk R. D. (1978) Critique of field trials with isotopically labelled nitrogen fertilizer. In Nitrogen Behaviour in Field Soil (D. R. Nielsen and J. G. MacDonald, Eds), pp. 63-77. Academic Press, New York.

Jarvis S. C., Barraclough D., Williams J. and Rook A. J. (1991) Patterns of denitrification loss from grazed grassland: effects of $\mathbf{N}$ fertilizer inputs at different sites. Plant and Soil 131, 77-88.

Jenkinson D. S., Fox R. H. and Rayner J. H. (1985) Interactions between fertilizer- $\mathrm{N}$ and soil- $\mathrm{N}$ : the socalled priming effect. Journal of Soil Science 36, 425444.

Knowles R. (1981) Denitrification. Ecological Bulletin 33 , 315-329.

Letey J., Valoras N., Hadas A. and Focht D. D. (1980) Effect of air-filled porosity, nitrate concentration and time on the ratio of $\mathrm{N}_{2} \mathrm{O} / \mathrm{N}_{2}$ evolution during denitrification. Journal of Environmental Quality 9, 227-231.
Nommik H. (1956) Investigations on denitrification in soil. Acta Agriculturae Scandinavica 6, 195-228.

Pain B. F., Thompson R. B., Rees Y. R. and Skinner J. H. (1990) Reducing gaseous losses of nitrogen from cattle slurry applied to grassland by the use of additives. Journal of the Science of Food and Agriculture 50, 141153.

Parkin T. B., Kaspar H. F., Sextone A. J. and Tiedje J. M. (1984) A gas-flow soil core method to measure field denitrification rates. Soil Biology \& Biochemistry 16, $323-330$.

Robertson G. P., Huston M. A., Evans F. C. and Tiedje J. M. (1988) Spatial variability in a successional plant community. Patterns of nitrogen mineralization, nitrification and denitrification. Ecology 69, 1517-1524.

Ryden J. C., Lund L. J. and Focht D. D. (1979) Direct measurement of denitrification loss from soils: 1 . Laboratory evaluation of acetylene inhibition of nitrous oxide reduction. Soil Science Society of America Journal 43, 104-1 10 .

Ryden J. C., Skinner J. H. and Nixon D. J. (1987) Soil core incubation system for the field measurement of denitrification using acetylene inhibition. Soil Biology \& Biochemistry 19, 753-757.

Scholefield D., Tyson K. C., Garwood E. A., Armstrong A. C., Hawkins J. and Stone A. C. (1993) Nitrate leaching from grazed grassland lysimeters: effects of fertilizer input, field drainage, age of sward and patterns of weather. Journal of Soil Science 44, 601-613.

Scholefield D., Hawkins J. M. B. and Jackson S. M. (1997) Use of a flowing helium atmosphere incubation technique to measure the effects of denitrification controls applied to intact cores of a clay soil. Soil Biology \& Biochemistry 29, 1337-1344.

Siegel R. S., Hauk R. D. and Kurtz L. T. (1982) Determination of ${ }^{30} \mathrm{~N}_{2}$ and application to measurement of $\mathrm{N}_{2}$ evolution during denitrification. Soil Science Society of America Journal 46, 68-74.

Stefanson R. C. (1970) Soil denitrification in sealed soilplant systems 1. Effect of plants, soil water content and organic matter content. Plant and Soil 33, 113-127.

Stefanson R. C. and Greenland D. J. (1970) Measurement of nitrogen and nitrous oxide evolution from soil-plant systems using sealed growth chambers. Soil Science 109, 203-206.

Wickramasinghe K. N., Talibudeen $O$. and Witty $J$. F. (1978) A gas flow-through system for studying denitrification in soils. Journal of Soil Science 29, 527-536. 